\title{
Composition/Phase Structure and Properties of Titanium-Niobium Alloys
}

\author{
Yen-Huei Hon ${ }^{1, * 1}$, Jian-Yih Wang ${ }^{2}$ and Yung-Ning Pan ${ }^{1, * 2}$ \\ ${ }^{1}$ Department of Mechanical Engineering, National Taiwan University, Taipei, Taiwan 106, R. O. China \\ ${ }^{2}$ Materials \& Electron-Optics Research Division, Chung-Shan Institute of Science and Technology, \\ Lung-Tan, Tao-Yuan, Taiwan 325, R. O. China
}

This study attempts to develop Ti-Nb alloys with elastic moduli that approach that of human bone. The experimental results reveal that the microstructure of a Ti-Nb alloy that contains 14 mass $\% \mathrm{Nb}$ consists of $\alpha$ and $\beta$ phases, with $\alpha$ phase being the dominant one. The proportion of the $\alpha$ phase decreases gradually as the $\mathrm{Nb}$ content increases, and the microstructure becomes completely the $\beta$ phase when the $\mathrm{Nb}$ content exceeds 34 mass $\%$. Moreover, the $\omega$ phase can be detected using XRD and TEM in alloys with a $\mathrm{Nb}$ content from 30 to 34 mass $\%$. Over the $\mathrm{Nb}$ range studied (14 to 40 mass \%), the elastic modulus decreases from 14 to 26 mass $\% \mathrm{Nb}$, and then increases to a maximum at $34 \mathrm{mass} \% \mathrm{Nb}$, before falling again as $\mathrm{Nb}$ content is increased further. The elastic modulus of the Ti-Nb alloys is closely related to the microstructure (or $\mathrm{Nb}$ content) of the alloys. The fall in the elastic modulus with the increasing Nb content from 14 to 26 mass $\%$ is associated with a gradual decrease in the proportion of the $\alpha$ phase in the microstructure, while the precipitation of the $\omega$ phase accounts for the increase in the elastic modulus over the intermediate range of $\mathrm{Nb}$ (30 to 34 mass\%). The tensile strength of Ti-Nb alloys increases slightly from 14 to 26 mass $\% \mathrm{Nb}$, and then increases markedly with a $\mathrm{Nb}$ content of up to 34 mass \%, before falling drastically as $\mathrm{Nb}$ content is increased further. A similar pattern was obtained for $0.2 \%$ proof stress, while the elongation vs. $\% \mathrm{Nb}$ curve was just the reverse of the T.S. vs. \% Nb curve, as expected. A Ti-Nb alloy with a relatively high $\mathrm{Nb}$ content (above 36 mass\%) is preferred to other compositions for use in medical implants with a reduced stress shielding effect.

(Received July 24, 2003; Accepted October 8, 2003)

Keywords: titanium-niobium alloys, microstructure, elastic modulus

\section{Introduction}

Titanium-based alloys are attractive implant materials owing to their high strength-to-weight ratio, excellent mechanical characteristics and bio-corrosion resistance, and satisfactory biocompatibility. ${ }^{1-4)}$ Ti-6Al-4V, the most common titanium alloy, is a good material for surgically implanted parts, such as knees, hips and shoulder replacements. However, the element $\mathrm{V}$ (vanadium), which is a strong $\beta$-stabilizing alloying element, has been found to react severely with tissue in animals. ${ }^{5-11)}$ Also, the use of $\mathrm{Al}$ (aluminum), an $\alpha$-stabilizing alloying element, is of concern, because it may be connected to neurological disorders and Alzheimer's disease..$^{7,11-13)}$ Hence, the synthesis of new titanium-based alloys, which are compatible with the human body, now involves more biocompatible metallic alloying elements, such as $\mathrm{Nb}$, Ta and $\mathrm{Zr}$. ${ }^{14,15)}$

Selecting materials for different components in implant prostheses depends on several factors, including the design and required strength of the system in application. Moreover, long-term studies have found that insufficient load transfer from an artificial implant to an adjacent remodeled bone may cause bone resorption and eventual loosening of the prosthetic device, ${ }^{16,17)}$ a phenomenon called "stress shielding effect". This so-called stress shielding effect is caused directly by the mismatch in the stiffness of the implant material with that of the surrounding natural bone. ${ }^{18-20)}$ Several solutions to this problem have been found, including more flexible designs and the use of materials with relatively low moduli.

An early attempt at reducing the elastic modulus of implant alloys was made by introducing $\alpha / \beta$-type Ti-6Al-4V titanium alloys, to yield elastic moduli $(\sim 108 \mathrm{GPa})$ of

\footnotetext{
${ }^{* 1}$ Graduate Student, National Taiwan University

${ }^{* 2}$ Corresponding author, E-mail: panyn@ccms.ntu.edu.tw
}

approximately half of those of SUS stainless steels ( $\sim 200 \mathrm{GPa})$ or Co-Cr-Mo alloys ( $210 \mathrm{GPa}){ }^{21,22)}$ However, the modulus of the $\alpha / \beta$-type titanium alloys is still considered high in relation to that of human bone (10$30 \mathrm{GPa}){ }^{22,23)}$ being 4-10 times its value. Recent attempts at further minimizing the modulus of implant alloys have led to the development of $\beta$-type titanium alloys, such as Ti-12Mo$6 \mathrm{Zr}-2 \mathrm{Fe}$ alloy and Ti-13Nb-13Zr alloy. The two aforementioned alloys have elastic moduli in the range of 74-88 GPa, but the values remain 2-7 times that of human bone. ${ }^{23}$ )

Recently developed biocompatible titanium-based alloys have tend to include relatively large amounts of $\mathrm{Nb}, \mathrm{Zr}$ and/ or Ta. ${ }^{23-28)}$ With respect to the elastic modulus, Davidson ${ }^{29)}$ reported that an $\mathrm{Nb}$ content in the range of 10-20 mass\% (preferably 14 mass\%) or in the range of 35-50 mass \% favors attaining a relatively low elastic modulus. Deviation from the above ranges tends to increase the elastic modulus.

What is the optimum amount of $\mathrm{Nb}$ required to yield mechanical properties, especially an elastic modulus, that is appropriate for implant applications? What is the mechanism by which mechanical properties change with $\mathrm{Nb}$ content? Neither question has yet been fully answered, and the present work seeks to elucidate the effect of $\mathrm{Nb}$ content on the phases or microstructures, as well as the mechanical characteristics, especially the elastic modulus, of the Ti-Nb alloys.

\section{Experimental Procedures}

\subsection{Alloy preparation}

Ti-Nb binary alloys, with $\mathrm{Nb}$ contents ranging from 14 to 40 mass $\%$ (in 4 mass $\%$ increments) were prepared using pure titanium (99.7 mass\% in purity) and niobium (99.8 mass\% in purity). The weighed charge materials (some 400 grams) were placed in a U-shaped water-cooled copper crucible and then melted using a non-consumable tungsten electrode arc in a vacuum chamber. The melting chamber was first evacuated 
Table 1 Chemical analysis of Ti-Nb alloys used in this study (mass\%).

\begin{tabular}{cccc}
\hline Alloy & $\mathrm{Nb}$ & $\mathrm{O}$ & $\mathrm{N}$ \\
\hline Ti-14Nb & 14.3 & 0.14 & 0.018 \\
Ti-18Nb & 18.2 & 0.15 & 0.014 \\
Ti-22Nb & 22.1 & 0.13 & 0.008 \\
Ti-26Nb & 25.8 & 0.12 & 0.008 \\
Ti-30Nb & 30.3 & 0.13 & 0.012 \\
Ti-32Nb & 32.3 & 0.13 & 0.012 \\
Ti-34Nb & 34.5 & 0.12 & 0.010 \\
Ti-36Nb & 36.6 & 0.12 & 0.012 \\
Ti-38Nb & 38.5 & 0.14 & 0.008 \\
Ti-40Nb & 40.7 & 0.13 & 0.007 \\
\hline
\end{tabular}

and then purged with argon. An argon pressure of $0.1 \mathrm{MPa}$ was maintained throughout melting. The alloys were remelted four more times to achieve chemical homogeneity. Table 1 gives chemical analyses of the prepared $\mathrm{Ti}-\mathrm{Nb}$ alloys, including data on $\mathrm{Nb}, \mathrm{O}$ and $\mathrm{N}$.

\subsection{Specimen preparation}

Solidified Ti-Nb alloy ingots were homogenized at $1273 \mathrm{~K}$ for $21.6 \mathrm{ks}$ at a vacuum of better than $0.27 \mathrm{~Pa}$, and then hotrolled at $1023 \mathrm{~K}$ into plates with a thickness of approximately $2 \mathrm{~mm}$. The final rolled specimens were again annealed at $973 \mathrm{~K}$ for $3.6 \mathrm{ks}$, and then cooled in a furnace to room temperature.

\subsection{Metallographic analysis}

The microstructures of the prepared specimens were examined after they had been metallographically polished, and then etched in Keller's reagent with $2 \mathrm{~mL} \mathrm{HF} / 3 \mathrm{~mL} \mathrm{HCl}$ / $5 \mathrm{~mL} \mathrm{HNO}_{3} / 190 \mathrm{~mL} \mathrm{H} \mathrm{H}_{2} \mathrm{O}$.

\subsection{XRD}

The phases were analyzed by X-ray diffraction (XRD) at $40 \mathrm{kV}$ and $30 \mathrm{mV}$. X-ray crystallography was performed using an Ni-filtered $\mathrm{Cu} \mathrm{K}_{\alpha}$ radiation source. Phases were identified by matching their characteristic peaks with those in the files of the Joint Committee on Powder Diffraction Standards (JCPDS).

\subsection{TEM}

TEM thin film specimens were prepared as follows. An Isomet cutter was used to slice the Ti-Nb alloy into $1 \mathrm{~mm}$ thick sheets, which were then mechanically ground to a thickness of $0.1 \mathrm{~mm}$. After the sheets were punched into discs with diameters of $3 \mathrm{~mm}$, the final TEM thin film specimens were prepared using a twin-jet electropolisher with a $10 \%$ $\mathrm{HClO}_{4}$ and a $90 \%$ ethanol mixture, until they were perforated. The microstructure was analyzed and the phases identified using a JEM-4000FX transmission electron microscope at an accelerating voltage of $400 \mathrm{kV}$; the point resolution was $0.26 \mathrm{~nm}$.

\subsection{Tensile test}

Figure 1 depicts the dimensions of the tensile specimens. Tensile tests of the Ti-Nb alloys with various $\mathrm{Nb}$ contents were performed at room temperature, with a strain rate of $3.33 \times 10^{-6} \mathrm{~m} / \mathrm{s}$. The determination of the elastic modulus

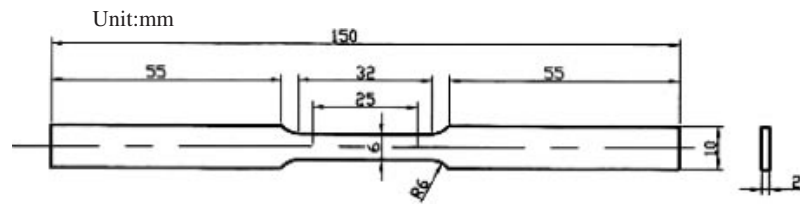

Fig. 1 Dimensions of the tensile test specimen.

proceeded according to ASTM E111-97, ${ }^{30)}$ which calculates the modulus from the ratio between the tensile stress and the corresponding strain up to the proportional limit of the alloy. The strain was determined using a clip-on extensometer attached to the specimen; the extensometer system was of class B-1, according to the ASTM E83-00 specifications. ${ }^{31)}$ Furthermore, the fracture surfaces of the tensile test specimens were analyzed by an SEM.

\section{Results and Discussion}

\subsection{Observations of microstructure}

Figure 2 shows typical SEM micrographs of Ti-Nb alloys with different $\mathrm{Nb}$ contents (14-40 mass\%). The microstructures of Ti-Nb alloys with $\mathrm{Nb}$ contents from 14 to 34 mass $\%$, consist of $\alpha$ and $\beta$ phases, and the fraction of the $\alpha$ phase decreases as the $\mathrm{Nb}$ content increases, as revealed in Figs. 2(a) to (f), in which the black (dark) regions represent $\alpha$ phase and the gray (light) regions represent $\beta$ phase, as verified by EDS analysis (Fig. 3). When the $\mathrm{Nb}$ content is further increased to exceed 34 mass $\%$ but under 40 mass $\%$, the microstructures are entirely of coarse $\beta$ phase, as shown in
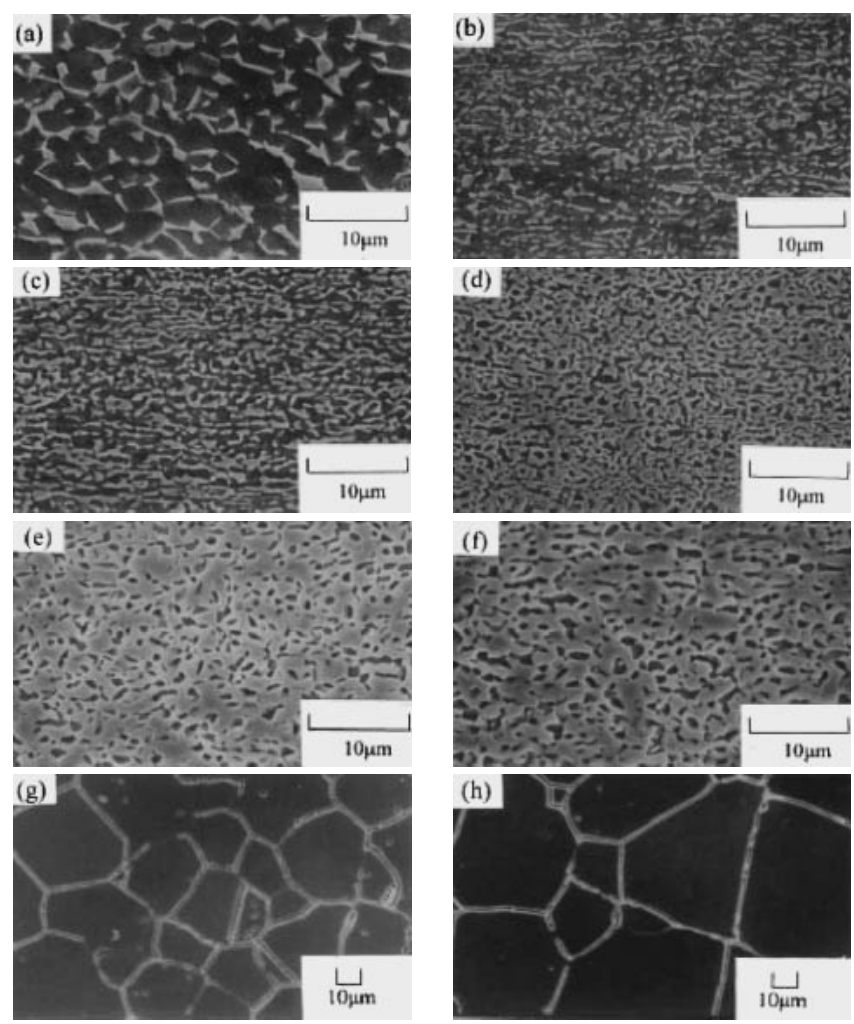

Fig. 2 A comparison of SEM micrographs of Ti-Nb alloys having various $\mathrm{Nb}$ contents (a) $14 \% \mathrm{Nb}$, (b) $18 \% \mathrm{Nb}$, (c) $22 \% \mathrm{Nb}$, (d) $26 \% \mathrm{Nb}$, (e) $30 \%$ $\mathrm{Nb}$, (f) $34 \% \mathrm{Nb}$, (g) $36 \% \mathrm{Nb}$, and (h) $40 \% \mathrm{Nb}$. 
$\alpha$-phase

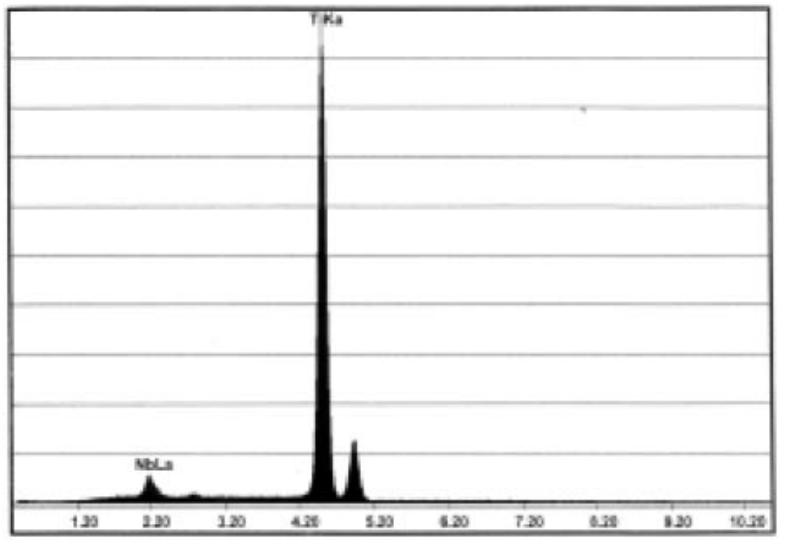

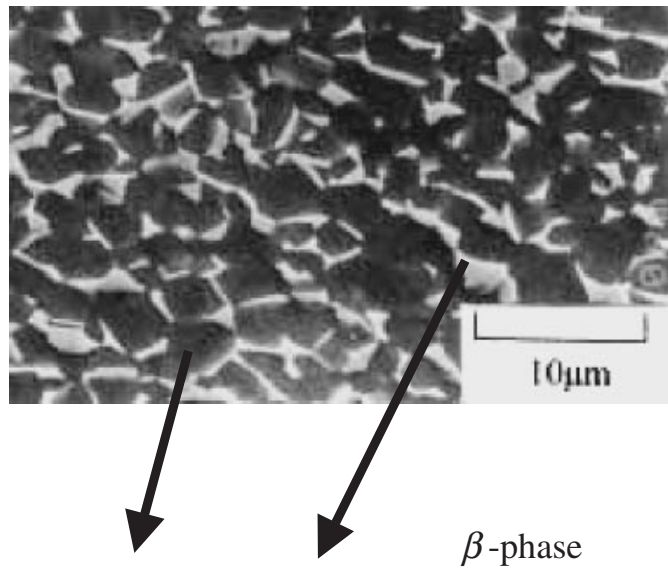

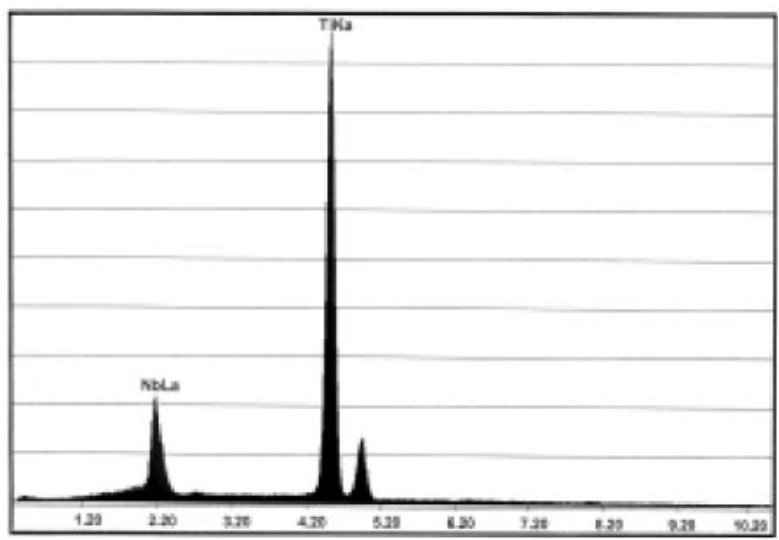

Fig. 3 EDS analysis results of different phases shown in Fig. 2(a).

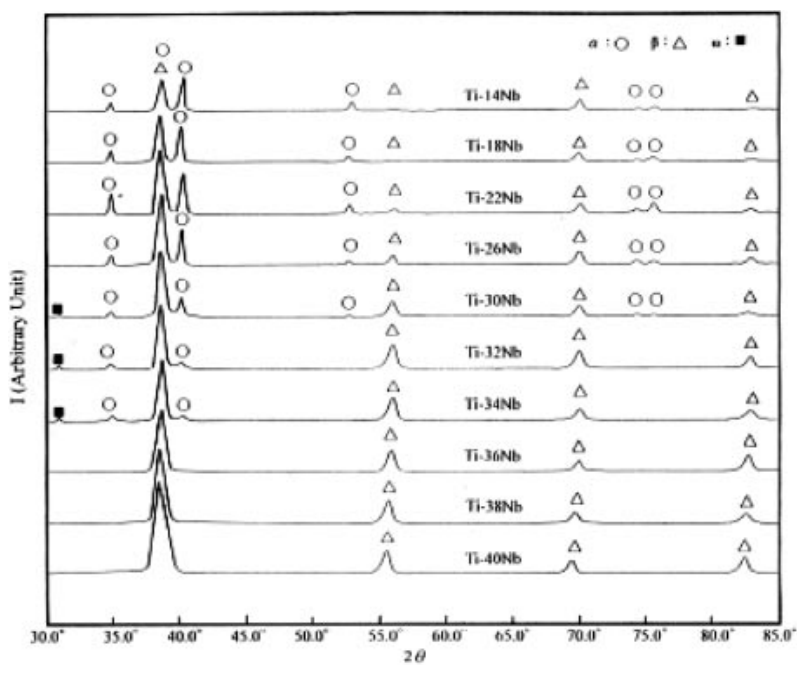

Fig. 4 X-ray diffraction patterns of Ti-Nb alloys.

Figs. 2(g) and (h).

\subsection{XRD analysis}

The phases in the Ti-Nb alloys were analyzed in detail using X-ray diffraction (XRD). Figure 4 displays the XRD patterns for a series of Ti-Nb alloys. The results reveal that the phases present in the $\mathrm{Ti}-\mathrm{Nb}$ alloys are related to the $\mathrm{Nb}$ content. The presence of both $\alpha$ and $\beta$ peaks is evident in an alloy with 14 mass $\% \mathrm{Nb}$. The primary $\alpha$ peak diminishes gradually as the $\mathrm{Nb}$ content increases, implying that the proportion of the $\alpha$ phase in the Ti-Nb alloys declines as the $\mathrm{Nb}$ content increases, and the original $\alpha$ phase-dominated structure gradually transforms into a $\beta$ phase-dominated structure. The $\alpha$ peaks completely disappear and only $\beta$ peaks remain when the $\mathrm{Nb}$ content exceeds 34 mass $\%$, as evident in the cases of 36 mass $\% \mathrm{Nb}, 38$ mass $\% \mathrm{Nb}$ and 40 mass $\% \mathrm{Nb}$. The XRD results are wholly consistent with the microstructure observations referred to above. The retention of the $\beta$ phase in Ti-Nb alloys at higher $\mathrm{Nb}$ contents is consistent with the results of Bania. ${ }^{32)}$ Bania reported that a molybdenum equivalent of over 10.0 (with an $\mathrm{Nb}$ content that exceeds 36 mass $\%$ ) is required to achieve a complete $\beta$ phase in the microstructure, upon quenching from a temperature above the $\beta$-transus temperature. $\omega$ peaks are sporadically obtained from alloys with $\mathrm{Nb}$ contents from 30 mass $\%$ to 34 mass $\%$. Williams $^{33)}$ and Balcerzak ${ }^{34)}$ observed this hexagonal $\omega$ phase in quenched $\mathrm{Ti}-\mathrm{Nb}$ alloys. The presence of a hexagonal isothermal $\omega$ phase is believed to exert a marked effect on the mechanical characteristics of $\mathrm{Ti}-\mathrm{Nb}$ alloys, as will be discussed below.

\subsection{TEM and SADP (Selected Area Diffraction Pattern) analyses}

Figure 5 displays a TEM image of a Ti-30\% Nb alloy at low magnification, revealing a distribution of needle-shaped $\alpha$ phases in a $\beta$-dominated matrix. Figure 6 respectively shows a bright-field TEM micrograph, a dark-field TEM micrograph, an SADP from the $\omega$ phase, and the interpretation of the SADP. The dark field image in Fig. 6(b) was taken from the $[0001]_{\omega}$ diffraction pattern. Note that the presence of the 

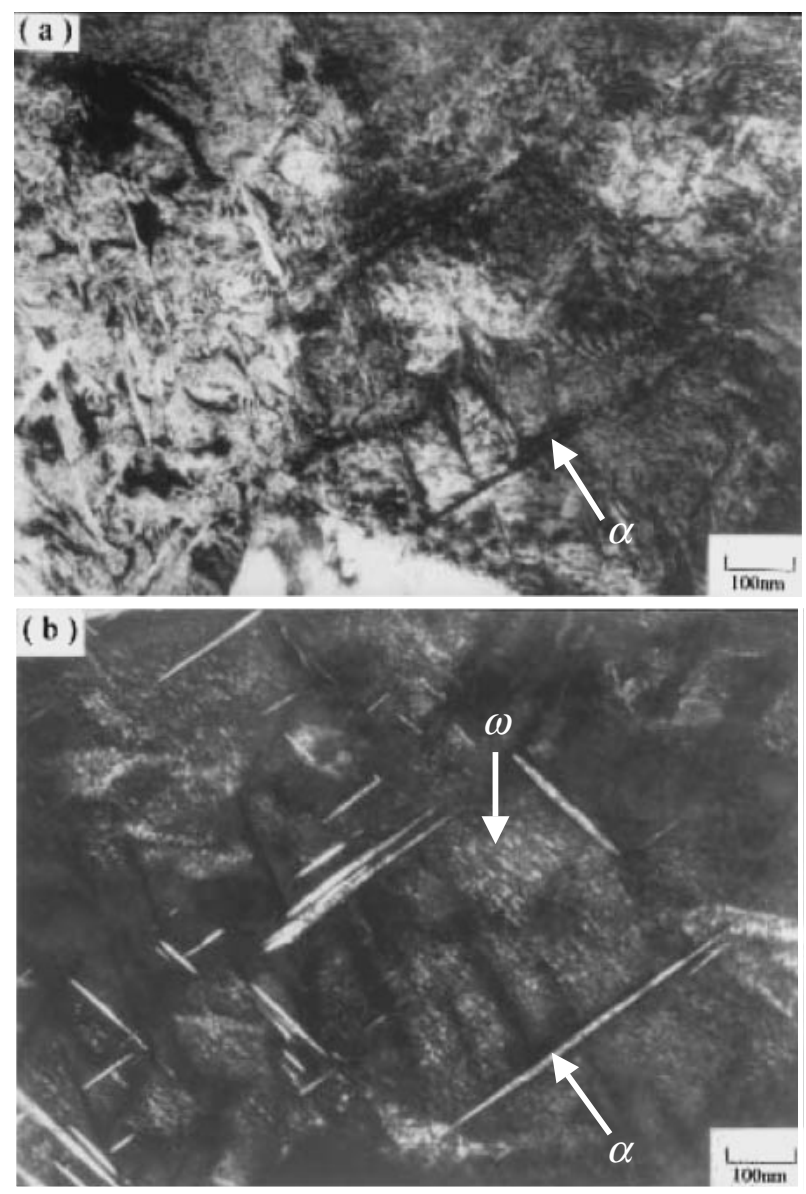

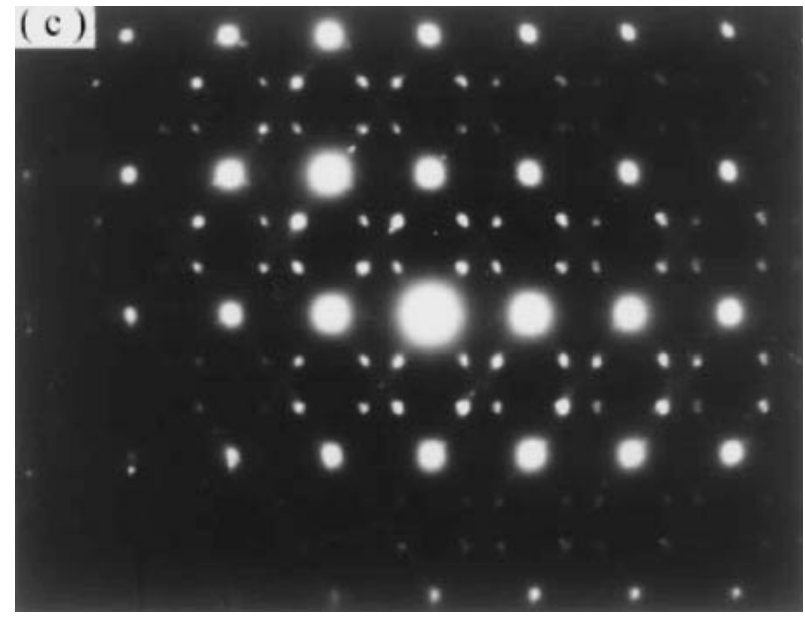

( d )

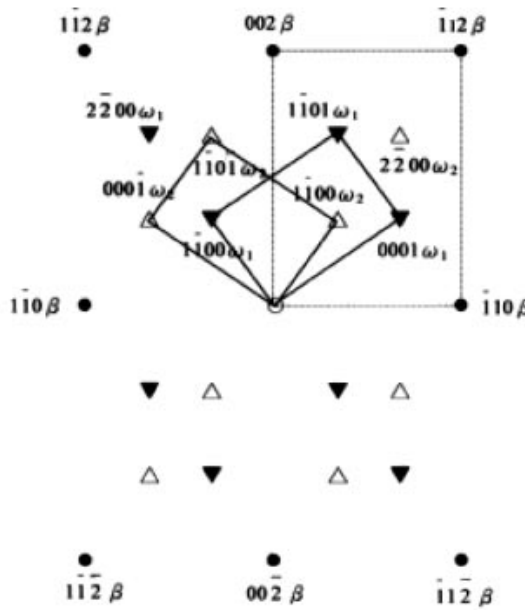

Fig. 6 TEM micrographs and SADP of Ti-30\%Nb alloy (a) the bright field image, (b) the dark field image, (c) SADP showing $\omega$ reflections, zone axes $[1 \overline{1} 0]_{\beta}$ and $[11 \overline{2} 0]_{\omega}$, and (d) an indexed diffraction pattern.

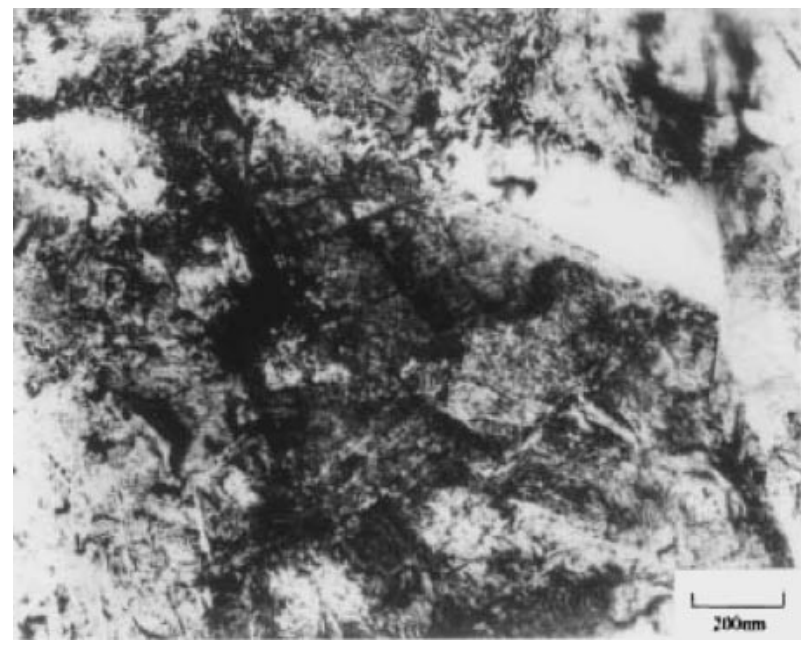

Fig. 5 TEM micrograph of Ti-30\% Nb alloy.

needle-like $\alpha$ phase in the dark field image is due to the fact that the aperture used was somewhat large to cover the diffraction spots associated with the $\alpha$ phase located near the target $\omega$ spots. Figure 6(d) clearly shows that, apart from the $\beta$ phase spots, several small spots that have been determined to represent two variants of the $\omega$ phase- $\omega_{1}$ and $\omega_{2}$. The $\omega$ spots are fainter and more diffuse than the $\beta$ spots. The diffusion of the $\omega$ spots is caused by their elongation in a preferred orientation and their minute size of the order of nano-meters, as can be revealed by the dark field TEM image (Fig. 6(b)). Orientation relationships between $\beta$ phase and $\omega$ phase were derived and are indicated below:

$$
\begin{aligned}
& {[1 \overline{1} 0]_{\beta} \|[11 \overline{1} 0]_{\omega}} \\
& (\overline{1} 11)_{\beta} \|(0001)_{\omega} \\
& (1 \overline{1} 2)_{\beta} \|(1 \overline{1} 00)_{\omega}
\end{aligned}
$$

\subsection{Elastic modulus}

Figure 7 plots change in the elastic modulus as a function of $\mathrm{Nb}$ content over the range studied (14-40 mass $\% \mathrm{Nb}$ ). The results show that the elastic modulus first declines as $\mathrm{Nb}$ content increases from 14 to 26 mass $\%$, and then increases as $\mathrm{Nb}$ content increases to 34 mass $\%$, before decreasing as the $\mathrm{Nb}$ content is increased further. Regression analysis was performed to determine the relationship between the elastic modulus and the $\mathrm{Nb}$ content. Three separate regions (or curves) were obtained, as described below. 


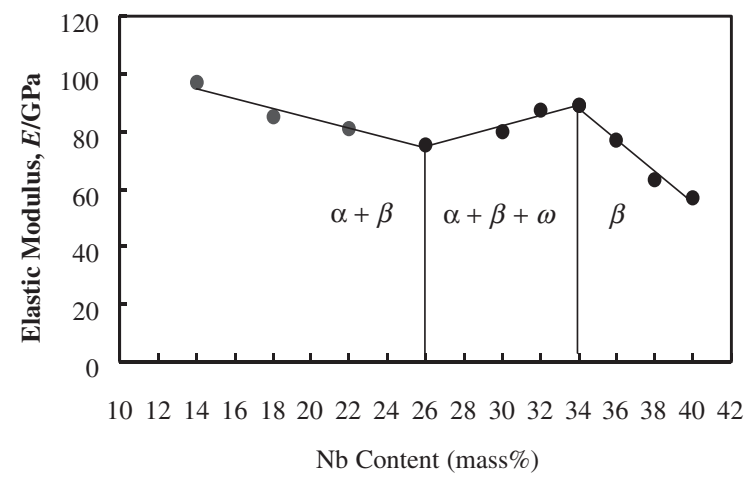

Fig. 7 Change in elastic modulus with increase of $\mathrm{Nb}$ content in the $\mathrm{Ti}-\mathrm{Nb}$ alloys.

For $14-26$ mass $\% \mathrm{Nb}: E_{\alpha+\beta}(\mathrm{GPa})=119.5-1.75(\% \mathrm{Nb})$

For $26-34$ mass $\% \mathrm{Nb}: E_{\alpha+\beta+\omega}(\mathrm{GPa})=26.5+1.84(\% \mathrm{Nb})$

For $34-40$ mass $\% \mathrm{Nb}: E_{\beta}(\mathrm{GPa})=275-5.5(\% \mathrm{Nb})$

Different phases ( $\alpha, \beta$ and $\omega$ ) have different elastic modulus, they are estimated to be related by $E_{\alpha} \fallingdotseq 1.5 E_{\beta}{ }^{35)}$ and $E_{\omega} \fallingdotseq 2.0 E_{\beta}{ }^{36)}$ The elastic modulus can be expected to decrease as $\mathrm{Nb}$ content increases because $\mathrm{Nb}$ reduces the proportion of $\alpha$ phase. Hence, the decrease in the elastic modulus as $\mathrm{Nb}$ content increases from 14 to 26 mass $\%$ is attributable to a gradual decrease in the amount of $\alpha$ phase (or an increase in the proportion of the $\beta$ phase) as the $\mathrm{Nb}$ content increases. The increase in the elastic modulus as $\mathrm{Nb}$ content increases between 26 mass $\%$ and 34 mass $\%$ is closely related to the appearance of $\omega$ phase in the microstructure, according to the XRD results discussed previously. The $\omega$ phase plays a significant role in increasing the modulus. However, when the $\mathrm{Nb}$ content exceeds 34 mass $\%$, not only does the $\omega$ phase disappear, but also the microstructure becomes entirely of the $\beta$ phase, so the elastic modulus begins to fall.

The elastic modulus generally decreases as $\mathrm{Nb}$ content increases, except in the intermediate range of $\mathrm{Nb}$ (3034 mass \%) in which the $\omega$ phase is present and the modulus is increased. Also, the stress shielding effect can be suppressed by employing alloys with an elastic modulus that approaches that of human bone (10-30 GPa). Hence, Ti-Nb alloys with a relatively high $\mathrm{Nb}$ content of above 34 mass $\%$ is a preferred choice as materials for medical implants.

\subsection{Tensile characteristics}

Figure 8 plots the change in tensile strength due to $\mathrm{Nb}$ content. The tensile strength of Ti-Nb alloys increases with $\mathrm{Nb}$ content, reaching a maximum at 34 mass $\% \mathrm{Nb}$, before decreasing with a further increase in $\mathrm{Nb}$ content. A detailed analysis of the T.S. vs. $\% \mathrm{Nb}$ curve reveals that the tensile strength increases slightly with $\mathrm{Nb}$ content from 14 to 26 mass $\%$, before increasing quickly with $\mathrm{Nb}$ content up to 34 mass $\%$, and then decreasing drastically with a further increase in $\mathrm{Nb}$ content. The trend of the $0.2 \%$ proof stress vs. $\% \mathrm{Nb}$ curve (Fig. 9) is similar to that of the tensile strength vs. $\% \mathrm{Nb}$ curve. For an $\mathrm{Nb}$ content between 14 and 26 mass\%, the increase in both tensile strength and $0.2 \%$ proof stress with $\mathrm{Nb}$ content is due to the increase in the proportion of the $\beta$ phase present. The precipitation of $\omega$ phase in alloys that

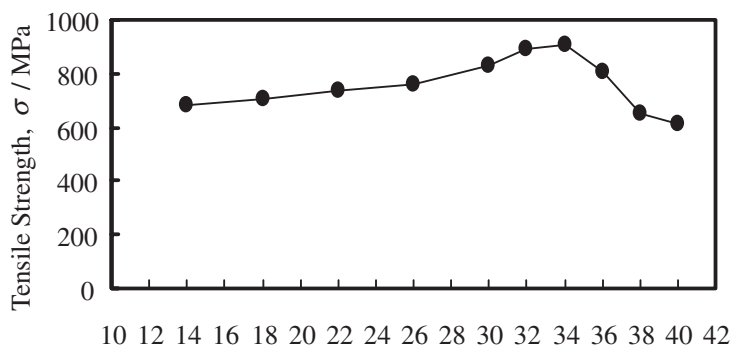

$\mathrm{Nb}$ Content (mass\%)

Fig. 8 Change in tensile strength with increase of $\mathrm{Nb}$ content in the $\mathrm{Ti}-\mathrm{Nb}$ alloys.

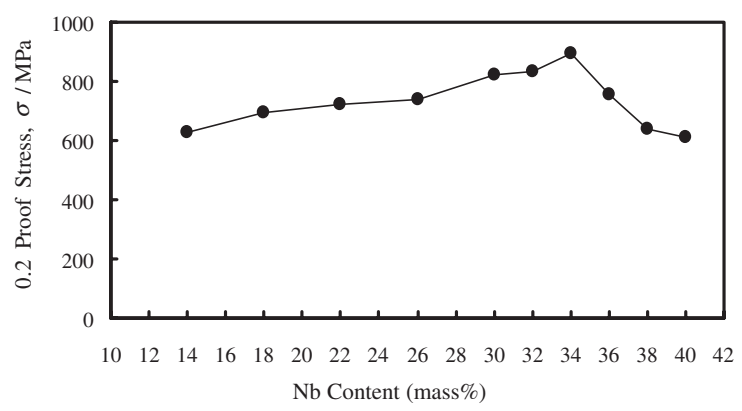

Fig. 9 Change in $0.2 \%$ proof stress with increase of $\mathrm{Nb}$ content in the $\mathrm{Ti}$ $\mathrm{Nb}$ alloys.

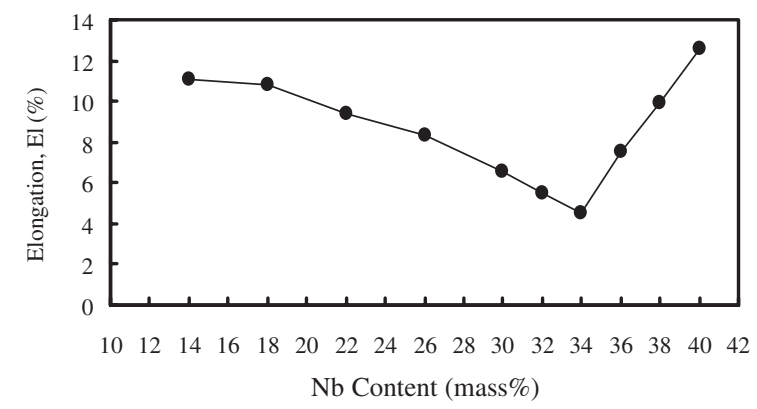

Fig. 10 Change in elongation with increase of $\mathrm{Nb}$ content in the $\mathrm{Ti}-\mathrm{Nb}$ alloys.

contain 30-34 mass $\% \mathrm{Nb}$ explains a relatively high rate of increase of strength. The subsequent sharp decrease in strength as $\mathrm{Nb}$ content increases may be attributable to the disappearance of the $\omega$ phase.

With respect to tensile ductility, the results plotted in Fig. 10 show that $\%$ elongation first decreases with increasing $\mathrm{Nb}$ content, reaching a minimum at 34 mass $\% \mathrm{Nb}$, before increasing with a subsequent increase in $\mathrm{Nb}$ content. The results, as expected, show just the reverse of both tensile and $0.2 \%$ proof stresses vs. $\% \mathrm{Nb}$ curves.

\subsection{Fractography}

Figure 11 presents the tensile fractographic structures of $\mathrm{Ti}-\mathrm{Nb}$ alloys obtained at various $\mathrm{Nb}$ contents. The fractured surfaces of $\mathrm{Ti}$ alloys that contain $14-30$ mass $\% \mathrm{Nb}$, exhibit primarily a finely dimpled morphology, characteristic of ductile fracture. The fractograph of the structure of a Ti alloy with 34 mass $\% \mathrm{Nb}$ reveals a predominant cleavage fracture surface. The brittle nature of the Ti-34\% $\mathrm{Nb}$ alloy is related to 

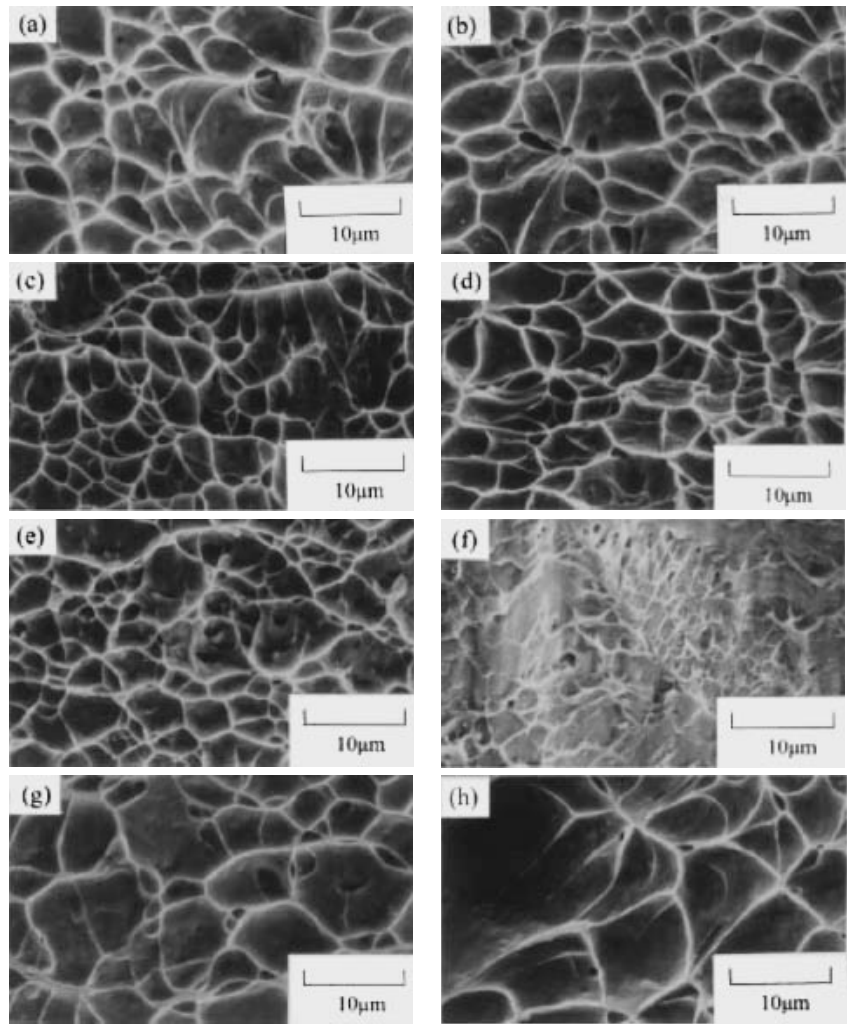

Fig. 11 A comparison of SEM fractographs of Ti-Nb alloys having various $\mathrm{Nb}$ contents (a) $14 \% \mathrm{Nb}$, (b) $18 \% \mathrm{Nb}$, (c) $22 \% \mathrm{Nb}$, (d) $26 \% \mathrm{Nb}$, (e) $30 \%$ $\mathrm{Nb}$, (f) $34 \% \mathrm{Nb}$, (g) $36 \% \mathrm{Nb}$, and (h) $40 \% \mathrm{Nb}$.

the presence of the $\omega$ phase in the microstructure, as discussed above. When the $\mathrm{Nb}$ content exceeds 34 mass\%, the fracture surface has a coarse dimpled morphology, which related to a single $\beta$ phase microstructure with relatively large grains in the alloys.

\section{Conclusions}

(1) The $\mathrm{Nb}$ content affects the microstructures of the $\mathrm{Ti}-\mathrm{Nb}$ alloys. The micro- structure of a Ti-Nb alloy that contains 14 mass $\% \mathrm{Nb}$ consists of $\alpha$ and $\beta$ phases, and the $\alpha$ phase is dominant. The proportion of $\alpha$ phase (or $\beta$ phase) decreases (or increases) gradually as the $\mathrm{Nb}$ content increases, and the microstructure becomes entirely $\beta$ phase when the $\mathrm{Nb}$ content exceeds 34 mass $\%$. Additionally, the $\omega$ phase can be detected using XRD and TEM in alloys with an $\mathrm{Nb}$ content from 30 to 34 mass $\%$.

(2) Within the $\mathrm{Nb}$ range studied (14-40 mass \%), the elastic modulus decreases first from 14 mass $\% \mathrm{Nb}$ to 26 mass $\%$ $\mathrm{Nb}$, and then increases to a maximum at 34 mass $\% \mathrm{Nb}$, before decreasing again as the $\mathrm{Nb}$ content is further increased. The elastic modulus of the Ti-Nb alloys is closely related to the microstructure (or $\mathrm{Nb}$ content) of the alloys. The fall in the elastic modulus with increasing $\mathrm{Nb}$ content from 14 to 26 mass $\%$ is due to a gradual decrease in the $\alpha$ proportion of phase, while the precipitation of the $\omega$ phase explains the increase in the elastic modulus in the intermediate range of $\mathrm{Nb}(30$ 34 mass $\%)$.
(3) The tensile strength of the Ti-Nb alloys increases slightly from 14 to 26 mass $\% \mathrm{Nb}$, and then increases markedly with the $\mathrm{Nb}$ content up to 34 mass $\% \mathrm{Nb}$, before falling drastically as the $\mathrm{Nb}$ content is increased further. The $0.2 \%$ proof stress exhibited a similar pattern.

(4) The results for tensile ductility reveal that \% elongation first declines as the $\mathrm{Nb}$ content increases; reaches a minimum at 34 mass $\% \mathrm{Nb}$, and then increases with a subsequent increase in $\mathrm{Nb}$ content. The \% elongation vs. $\% \mathrm{Nb}$ curve is just the reverse of the T.S. vs. $\% \mathrm{Nb}$ curve, as expected.

(5) A Ti-Nb alloy with a relatively high $\mathrm{Nb}$ content (above $36 \mathrm{mass} \%$ ) is preferable for use as medical implants and reducing stress shielding effect. The results of this work show that the $\mathrm{Ti}-40 \% \mathrm{Nb}$ alloy has an elastic modulus of some $57 \mathrm{GPa}$, a reasonably high ductility $(\sim 13 \%$ elongation), a moderate tensile strength $(\sim 600 \mathrm{MPa})$ and essentially a ductile fracture nature.

\section{Acknowledgments}

The authors would like to thank the National Science Council of the Republic of China, Taiwan for financially supporting this research under Contract No. NSC92-2216-E002-024.

\section{REFERENCES}

1) U. Zwiker, K. Buhler and R. Muller: Titanium'80 Science and Technology, ed. by H. Kimura and O. Izumi, (AIME, NY, 1980) pp. 505-514.

2) M. J. Donachie, Jr: A Technical Guide (ASM international, Metals Park, OH, 1988) pp. 1-19.

3) P. J. Bania: Beta Titanium Alloys in the 1990's, ed. by D. Elylon, R. R. Boyer and D. A. Koss, (TMS, Warrendale, PA, 1993) pp. 3-14.

4) M. N. iinomi: Structure Biomaterials for the 21st Century, ed. by M. Niinomi, T. Okabe, E. M. Taleff, D. R. Lesure and H. E. Lippare, (TMS, Warrendale, PA, 2001) pp. 3-14.

5) Y. Okazaki, Y. Ito, K. Kyo and T. Tateishi: Mater. Sci. Eng. A213 (1996) 138-147.

6) S. Rao, T. Ushida, T. Tateishi, Y. Okazaki and S. Asao: Biomed. Mater. Eng. 6 (1996) 79-86.

7) P. R. Walker, J. Leblanc, M. Silorska: Biochemistry 28 (1989) 39113915.

8) P. G. Laing, A. B. Fergosun, JR. and E. S. Hodge: J. Biomed. Mater. Res. 1 (1967) 135-149.

9) S. G. Steinemann: Evaluation of Biomaterials, ed. by G. D. Winter, J. L. Leray and K. De Groot, (John Wiley \& Sons Ltd., NY, 1980) pp. $1-34$.

10) D. R. C. Mclachlan, B. Farnell and H. Galin: Biological Aspects of Metals and Metal-Related Disease. ed. by B. Sarkar (Raven Press, NY, 1983) pp. 209-218.

11) S. G. Steinemann: Titanium'84: Science and Technology, ed. by G. Lüjering, U. Zwicker and W. Bunk, (Deutsche Gesellschaft Für Metallkunde, Munich, Germany, 1985) pp. 1373-1379.

12) D. P. Perl and A. R. Brody: Sci. 208 (1980) 297-308.

13) S. Yumoto, H. Ohashi, H. Nagai, S. Kakimi Y. Ogawa, Y. Iwata and K. Ishii: Int. J. PIXE 2 (1992) 493-504.

14) S. G. Steinemann: Eavaluation of Biomaterials, ed by G. D. Winter, J. L. Leray and K. de Groot, (John Wiley \& Sons Ltd., NY, 1980) pp. 1-34.

15) H. Kawahara, S. Ochi, K. Tanetani, K. Kato, M. Isogai, Y, Mizuno, H. Yamamoto and A. Yamaguchi: J. Jpn. Soc. Dent. Apparat. \& Mater. 4 (1963) 66-75.

16) A. R. Dujovne, J. D. Bobyn, J. J. Krygier, J. E. Miller and C. E. Brooks: 
J. Arthroplasty 8 (1993) 7-22.

17) C. A. Engh and J. D. Bobyn: Clin. Orthop. Relat. Res. 231 (1988) 7-28.

18) D. R. Sumner and J. O. Galante: Clin. Orthop. Relat. Res. 274 (1992) 202-212.

19) A. Sarmiento, G. A. Zych, L. L. Latta and R. R. Tarr: Clin. Orthop. Relat. Res. 144 (1979) 166-173.

20) M. F. Semlitsch, H. Weber, R. M. Streicher and R. Schon: Biomaterials 13 (1992) 781-788

21) R. M. Pillar: Biomaterials 12 (1991) 95-100.

22) M. Niinomi, T. Hattori, K. Morikawa, T. Kasuga, A. Suzuki, H. Fukui and S. Niwa: Mater. Trans. 43 (2002) 2970-2977.

23) M. Long, H. J. Rack: Biomaterials 19 (1998) 1621-1639.

24) M. Niinomi: Mater. Sci. Eng. A243 (1996) 231-236.

25) A. K. Mishra, J. A. Davidson, R. A. Poggie, P. Kovacs and T. J. Fitzgerald: Medical Applications of Titanium and Its Alloys, ed by S. A. Brown and J. E. Lemons, (ASTM STP 1272, West Conshohocken, PA, 1996) pp. 96-113.

26) V. Tang, T, Ahmed and H. J. Rack: J. Mater. Sci. 35 (2000) 1805-1811
27) M. Niinomi: Metall. Mater. Trans. A 33A (2002) 477-486.

28) T. Ahmed and H. J. Rack, U. S. Patent No. 5871595, 1999

29) J. A. Davidson and P. Kovacs, U. S. Patent No. 5954724, 1992.

30) ASTM designation E111-97: Standard test method for Young's modulus, tangent modulus and chord modulus, (ASTM, Philadelphia. PA, U.S.A., 2002) pp. 1-7.

31) ASTM designation E83-00: Standard practice for verification and classification of extensometer system, (ASTM, Philadelphia, PA, U.S.A., 2002) pp. 1-12.

32) P. J. Bania: Beta Titanium Alloys in the 1990's, ed. by D. Elylon, R. R. Boyer and D. A. Koss, (TMS, Warrendale, PA, 1993) pp. 3-14.

33) J. C. Williams: Titanium Science and Technology, ed. by R. I. Jaffee and H. M. Burte, (AIME, Plenum Press, NY, 1973) pp. 1433-1494.

34) A. T. Balcerzak and S. L. Sass: Metall. Mater. Trans. A 3 (1972) 16011605 .

35) F. R. Larson and A. Zarkades: MCIC Report 74-20 (1974)

36) A. W. Bowen: Scr. Meter. 5 (1971) 709-715. 